\title{
Mechanism for Modulation of Nicotinic Acetylcholine Receptors That Can Influence Synaptic Transmission
}

\author{
Mariano Amador and John A. Dani \\ Division of Neuroscience, Baylor College of Medicine, Houston, Texas 77030-3498
}

Only recently has it been appreciated that neuronal nicotinic ACh receptors (NnAChRs) are highly permeable to $\mathrm{Ca}^{2+}$ and are modulated by $\mathrm{Ca}^{2+}$ in a dose-dependent manner. These findings suggest that $\mathrm{Ca}^{2+}$ could have roles in cholinergic synaptic plasticity. We report a possible mechanism for $\mathrm{Ca}^{2+}$-initiated synaptic plasticity that differs from the intracellular $\mathrm{Ca}^{2+}$ cascade associated with plasticity of glutamatergic synapses. Rapid changes in external $\mathrm{Ca}^{2+}$ modulate cholinergic spontaneous synaptic currents in superior cervical ganglionic sympathetic neurons. Inhibition of cholinergic currents by chlorisondamine, which blocks only open channels and becomes trapped in the pore, showed that the modulation is not by a mechanism that activates a previously unresponsive population of NnAChRs. Rather, single-channel recordings with ganglionic NnAChRs from chromaffin cells indicated that $\mathrm{Ca}^{2+}$ directly alters the probability of the channels being open. We hypothesize from the results that activity-dependent decreases in external $\mathrm{Ca}^{2+}$, which occur throughout the nervous system, could directly underlie a rapid negative-feedback mechanism that decreases the responsiveness of NnAChRs at synapses. When external $\mathrm{Ca}^{2+}$ is decreased, presynaptic $\mathrm{Ca}^{2+}$ currents and transmitter release also are diminished. Thus, several mechanisms could combine to potently and rapidly depress synaptic nicotinic receptors until the external $\mathrm{Ca}^{2+}$ concentration recovers.

[Key words: synaptic modulation, calcium, calcium modulation, cholinergic, neuronal ACh receptors, nicotine]

Neuronal nicotinic ACh receptors (NnAChRs) are found throughout the CNS and PNS. It was recently shown that NnAChRs have a high $\mathrm{Ca}^{2+}$ permeability (Adams and Nutter, 1992; Mulle et al., 1992a; Vernino et al., 1992, 1994). Permeability ratio measurements indicated that a NnAChR subtype composed of the $\alpha 7$ subunit has an even higher $\mathrm{Ca}^{2+}$ permeability, comparable to the permeability of the NMDA subtype of glutamate receptors (Séguéla et al., 1993). At glutamatergic synapses, $\mathrm{Ca}^{2+}$ influx through NMDA receptors

Received Dec. 19, 1994; accepted Feb. 2, 1995

Chlorisondamine was a gift from Dr. Richard A. Lovell, CIBA-GEIGY Corp. We thank Dr. R. A. J. Lester for commenting on the manuscript. This work was supported by the Muscular Dystrophy Association, the American Heart Association, and NIH (NINDS) Grant NS 21229.

Correspondence should be addressed to John A. Dani at the Division of Neuroscience, Baylor College of Medicine, One Baylor Plaza, Houston, TX $77030-3498$

Copyright (C) 1995 Society for Neuroscience $\quad 0270-6474 / 95 / 154525-08 \$ 05.00 / 0$ enhances protein kinase activity, which is an early step in the process of long-term potentiation (Malinow el al., 1988; Malenka et al., 1989; Madison et al., 1991). At highly active cholinergic synapses, $\mathrm{Ca}^{2+}$ influx through $\mathrm{NnAChRs}$ could activate similar intracellular mechanisms, but such mechanisms have not yet been observed at central cholinergic synapses.

The present study focuses on the mechanism and potential for synaptic plasticity arising from another aspect of $\mathrm{Ca}^{2+}$ modulation that is unique to neuronal nAChRs. External $\mathrm{Ca}^{2+}$ enhances NnAChR responses in a dose-dependent manner (Mulle et al., 1992a; Vernino ct al., 1992). Applications of nicotinic agonist to a cholinoceptive neuron induce progressively smaller responses as external $\mathrm{Ca}^{2+}$ is decreased. The modulation is seen in a concentration range of $\mathrm{Ca}^{2+}$ from 0 to $10 \mathrm{mM}$ and is strongest at the physiologic level of about $1 \mathrm{mM}$ after correcting for the permeation properties of nAChRs for $\mathrm{Ca}^{2+}$ (Decker and Dani, 1990; Mulle et al., 1992b; Vernino et al., 1992). This modulation of NnAChRs by external $\mathrm{Ca}^{21}$ can be of biological importance because high synaptic activity can produce millimolar reductions in external $\mathrm{Ca}^{2+}$ (Benninger et al., 1980; $\mathrm{Pu}$ main and Heinemann, 1985; Mody and Heinemann, 1986; Heinemann et al., 1990; Livsey et al., 1990). These activity-dependent changes in extracellular $\mathrm{Ca}^{2+}$ were measured using electrodes that averaged over a relatively large volume. Because the local density of current in the small cleft of an active synapse can be higher than the average current density in a large volume of neurons, the $\mathrm{Ca}^{2+}$ reduction within a synaptic cleft could be significantly greater than estimated using extracellular electrodes. We report here that changes in external $\mathrm{Ca}^{2+}$ act on NnAChRs to modify spontaneous cholinergic synaptic currents. Therefore, activity-dependent reductions in external $\mathrm{Ca}^{2+}$ could cause a rapid negative feedback onto cholinergic synaptic transmission. Our results indicate that $\mathrm{Ca}^{2+}$ does not activate a previously unresponsive population of $\mathrm{Nn}$ AChRs. Rather, $\mathrm{Ca}^{2+}$ increases the likelihood that responsive $\mathrm{Nn} \Lambda \mathrm{ChRs}$ will be open in the presence of agonist.

\section{Materials and Methods}

Cell culture. Sympathetic neurons were isolated from the superior cervical ganglia (SCG) of neonatal rats. During the first few days in culture, these neurons are adrenergic. When grown in coculturc with cardiac muscle cells or in conditioned media, the neurons become cholinergic (Hawrot and Patterson, 1979). We grew cardiac cells on the bottom of culture dishes. Hearts from newborn rats were minced dissociated with divalent-free solutions in $1 \mathrm{mg} / \mathrm{ml}$ collagenase, triturated, washed, and plated. The cardiac cells matured and covered the bottom of the dish in a few days. Then, poly-D-lysine/collagen coated cover-glass slips were placed on top of the cardiac cells. SCG neurons were plated onto the cover glass. After 7 or more days in culture, cholinergic/cholinoceptive synapses formed among the SCG neurons on the cover glass. The neurons were obtained from a pair of SCG by 
dissecting away the capsule and cutting the SCG into two pieces in Dulbecco's modified Eagle medium (DMEM). The pieces were incubated in $6 \mathrm{ml}$ of $0.15 \%$ trypsin (GIBCO) for $15 \mathrm{~min}$. After several trituration steps, the cells were placed into DMEM with $10 \%$ letal bovine serum (FBS), pelleted, resuspended, and plated onto the cover glass in $10 \%$ FBS in DMEM with $25 \mathrm{ng} / \mathrm{ml}$ nerve growth factor (NGF 7S, Cambridge Res. Biochem.). After about three days, the cells were treated with $5 \mu \mathrm{M}$ cytosine arabinofuranoside.

Ganglionic-type nAChR channels also were studied in bovine chromaffin cells that were prepared using standard techniques (Greenberg and Zinder, 1982) as we have described previously (Vernino et al., 1992). Fresh adrenal glands were collected from a slaughterhouse, washed, and perfused by $0.25 \%$ collagenase through the adrenal vein. The medulla was dissected from the cortex, minced, and treated with collagenase for a total of $90 \mathrm{~min}$. Several steps of centrifugation through a fetal calf serum/Locke's solution pad (1:1) were used to purify the chromaffin cells. Then the cells were resuspended and plated in DMEM (Hazleton or GIBCO) containing $10 \%$ heat inactivated FBS (GIBCO or Hyclone), $100 \mathrm{U} / \mathrm{ml}$ of penicillin, $100 \mu \mathrm{g} / \mathrm{ml}$ of streptomycin (Hazleton), and $2 \mathrm{~mm}$ glutamine (Hazleton) in an incubator at $37^{\circ} \mathrm{C}$ with $5 \% \mathrm{CO}_{2}$. The cells were plated onto collagen-coated cover glass and were used 5-20 d after being plated.

Patch-clamp recordings. Whole-cell and single-channel NnAChR currents were measured in sympathetic neurons and chromaffin cells using standard patch-clamp techniques (Hamill et al., 1981) as we have described previously (Amador and Dani, 1991; Vernino et al., 1992). Patch pipettes were pulled in two stages (PP-83, Narishige USA) using glass tubes (Garner Glass Co.). To decrease capacitive noise, the pipettes were coated with Sylgard silicon elastomer. Pipette tips were polished immediately before the experiment using a microforge (Narishige USA) to a final resistance of 2-4 M $\Omega$ in our solutions. Currents were amplified and filtered (four-pole Bessel filter) using an Axoclamp patch-clamp amplifier and were collected and analyzed using AXOBASIC and pCIAMP programs (Axon Inst). The singlechannel currents were sampled at $10 \mathrm{kHz}$ and were filter at $2 \mathrm{kHz}$. For all the experiments with synaptically coupled SCG neurons, the holding potential was $-70 \mathrm{mV}$. The spontaneous synaptic currents were judged to be cholinergic if they were blocked by the cholinergic antagonist, hexamethonium. Occasionally very small currents were seen in hexamethonium, but they were rapid and did not have the slow falling phase typical of synaptic currents.

Solutions. For all of the experiments except those conducted on synaptically coupled SCG neurons, the solutions were as follows: external, $150 \mathrm{~mm} \mathrm{CsCl}, 20 \mathrm{~mm}$ HEPES, $10 \mathrm{~mm}$ glucose, $1 \mu \mathrm{m}$ atropine, $1 \mu \mathrm{M}$ TTX, and $0 \mathrm{Ca}^{2+}+1 \mathrm{~mm}$ EGTA or $1 \mathrm{mM} \mathrm{CaCl}_{2}$ or $10 \mathrm{~mm}$ $\mathrm{CaCl}_{2}$; internal, $140 \mathrm{mM} \mathrm{CsCH}_{3} \mathrm{SO}_{3}, 5 \mathrm{mM} \mathrm{NaCl}, 20 \mathrm{~mm}$ HEPES, 10 mM BAPTA, with or without $4 \mathrm{~mm}$ ATP-Mg. To measure spontaneous synaptic currents (SSCs) from synaptically coupled SCG neurons, the solutions were the same as above except external $\mathrm{CsCl}$ was replaced by $\mathrm{NaCl}$, and the external $\mathrm{CaCl}_{2}$ concentration was usually 1,2 , or 5 $\mathrm{mm}$. Since we have shown previously the $\mathrm{Ca}^{2+}$ modulation occurs over a range from 0 to $10 \mathrm{~mm}$ (Vernino et al., 1992), we chose external $\mathrm{Ca}^{2+}$ concentrations that were physiologically reasonable but also were conducive for long-lasting recordings, which were more difficult in $\mathrm{Ca}^{2+}$ concentrations below 1 or $2 \mathrm{~mm}$. Also, below $1 \mathrm{~mm} \mathrm{Ca}^{2+}$, the cholinergic currents become smaller because of $\mathrm{Ca}^{2+}$ modulation, and therefore, measurements cannot be as precise. The $\mathrm{pH}$ was adjusted to 7.35 with the base of the main ion, and the osmolality was adjusted to $300 \mathrm{mOsm}$ with $\mathrm{NaCl}$.

Fast solution changes, to change the external $\mathrm{Ca}^{2+}$ solution or to apply agonist, usually were made with large outflow tubes $(375 \mu \mathrm{m}$ inner diameter glass pipettes) that were positioned in a row next to each other as we have described previously (Amador and Dani, 1991). The outflow tubes were mounted on a high speed motorized manipulator (Newport Corp.) so that they could be repositioned rapidly for solution changes that were complete in tens of milliseconds.

\section{Results}

$\mathrm{Ca}^{2+}$ acts externally to modulate NnAChRs

External $\mathrm{Ca}^{2+}$ enhances currents induced by exogenous application of the specific nicotinic agonist, DMPP, to a SCG neuron (Fig. $1 A$ ) or a chromafin cell (Fig. $1 B$ ). The currents induced by $56 \mu \mathrm{M}$ DMPP are larger in a solution containing $1 \mathrm{mM} \mathrm{Ca}^{2+}$ as compared with an identical $\mathrm{Ca}^{2+}$-free solution, indicating
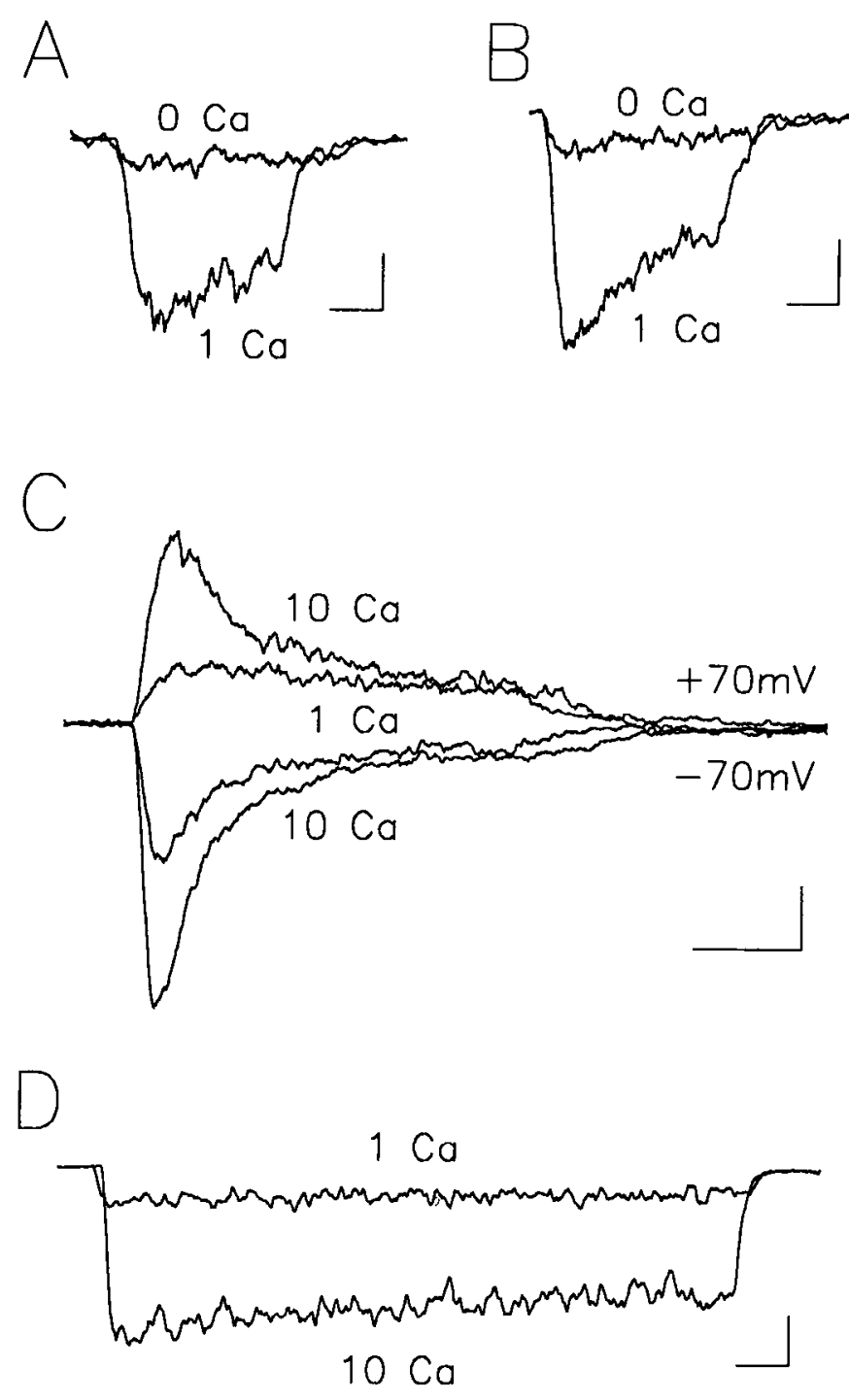

Figure 1. Physiologic concentrations of $\mathrm{Ca}^{2+}$ act externally to modulate NnAChRs. A, NnAChRs from SCG neurons were activated by whole-cell application of $56 \mu \mathrm{M}$ DMPP, a specific nicotinic agonist. I he agonist-induced current in $1 \mathrm{mM} \mathrm{Ca}^{2+}$ is 5.5 times larger than the current activated by the same agonist application in a $\mathrm{Ca}^{2+}$-free external solution (containing $1 \mathrm{~mm}$ EGTA). The holding potential was $-70 \mathrm{mV}$. Calibration: 25 pA, $250 \mathrm{msec} . B$, Exactly as in $A$, ganglionic NnAChRs from adrenal chromaffin cells were activated in 0 and $1 \mathrm{~mm} \mathrm{Ca}{ }^{2+}$. The current are five times larger in the solution of $1 \mathrm{~mm} \mathrm{Ca}^{2+}$. Calibration: $50 \mathrm{pA}, 250 \mathrm{msec}$. $C$, Four currents from an adrenal chromaffin cell activated by $32 \mu \mathrm{M}$ DMPP are shown. The enhancement in the currents in $10 \mathrm{mM} \mathrm{Ca}^{2+}$ as compared with $1 \mathrm{mM} \mathrm{Ca}^{2+}$ are similar at both holding potentials: threefold at $+70 \mathrm{mV}$ and twofold at $-70 \mathrm{mV}$. For the currents that arc shown, the cells were internally perfused with $10 \mathrm{~mm}$ BAPTA. Calibration: $200 \mathrm{pA}, 250 \mathrm{msec}$. $D$, In this chromaffin cell, the current in $10 \mathrm{mM} \mathrm{Ca}^{2+}$ is 4.1 times larger than in $1 \mathrm{mM} \mathrm{Ca}^{2}$. Although the agonist ( $32 \mu \mathrm{M}$ DMPP) was applied for more than twice as long as in $C$, there is much less desensitization. The holding potential was -70 $\mathrm{mV}$. Calibration: $50 \mathrm{pA}, 250 \mathrm{msec}$.

that $\mathrm{Ca}^{2+}$ modulates NnAChRs. The 1 IIIM $\mathrm{Ca}^{2+}$ enhanced currents from chromaffin cells by $5.4 \pm 0.7(\mathrm{SE}, n=3)$ and from SCG neurons by $5.5,5.0(n=2) . \mathrm{Ca}^{2+}$ is not a coagonist, however, because there are small agonist-induced currents even in the $\mathrm{Ca}^{2+}$-free solution.

Consistent with previous work (Mulle et al., 1992b; Vernino et al., 1992), Figure $\mathrm{I}$ illustrates that $\mathrm{Ca}^{2+}$ acts externally to 


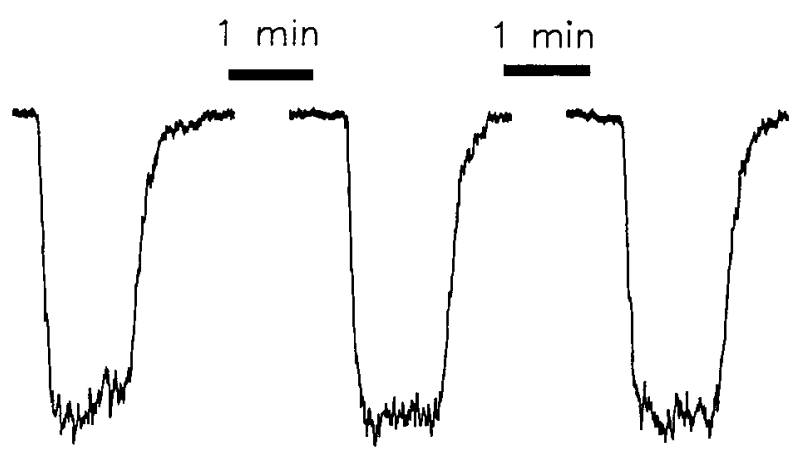

A

$1 \mathrm{Ca}$
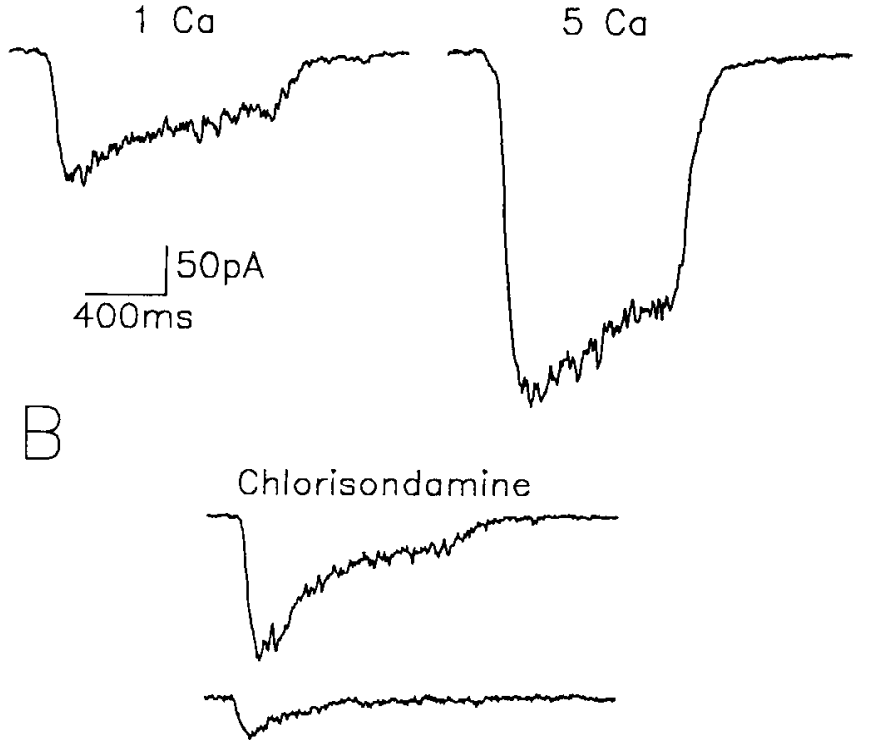

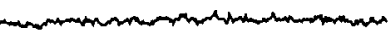

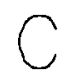

$1 \mathrm{Co}$
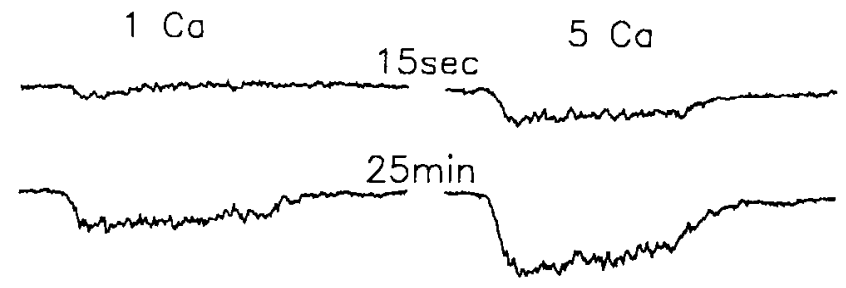

Figure 3. External $\mathrm{Ca}^{2+}$ does not enhance $\mathrm{NnAChR}$ currents by activating an otherwise unresponsive population of channels. $A$, Currents activated in a sympathetic neuron by $32 \mu \mathrm{M}$ DMPP are three times larger in $5 \mathrm{mM}$ versus $1 \mathrm{mM} \mathrm{Ca}^{2+} . B$, In the $1 \mathrm{mM} \mathrm{Ca}^{2+}$ solution, the cell was stimulated by $32 \mu \mathrm{M}$ DMPP in the presence of the open-channel blocker. $5 \mu \mathrm{M}$ chlorisondamine, every $12 \mathrm{sec}$ for $3 \mathrm{~min}$. The top record shows the first DMPP application. The falling phase of the current is mostly attributable to chlorisondamine entering and blocking channels after they open. The middle record was obtained after $1 \mathrm{~min}$. The bottom record was the last agonist application after all the channels that open in $1 \mathrm{~mm}$ $\mathrm{Ca}^{2+}$ were blocked. $C$, After washing the chlorisondamine away for 15 sec, agonist was applied again, first in $5 \mathrm{~mm}$ then in $1 \mathrm{~mm} \mathrm{Ca}^{2+}$. The current is three times larger in $5 \mathrm{mM} \mathrm{Ca}^{2+}$. After 10 agonist applications and $25 \mathrm{~min}$ of washing, the currents have recovered more from chlorisondamine blockade, but the enhancement by $5 \mathrm{~mm} \mathrm{Ca}^{2+}$ is still threefold. The holding potential was always $-70 \mathrm{mV}$.

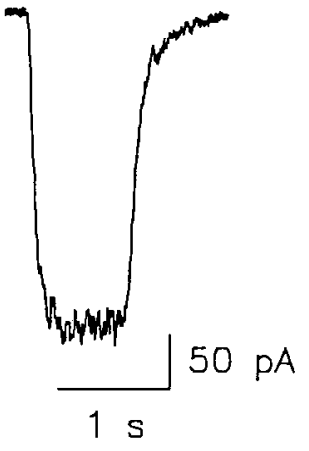

Figure 2. Chlorisondamine does not block closed NnAChRs. Four currents are shown from a SCG sympathetic neuron induced by application of 56 $\mu \mathrm{M}$ nicotine at a holding potential of $-70 \mathrm{mV}$ in a solution containing $5 \mathrm{~mm}$ $\mathrm{Ca}^{2+}$. The nicotine applications are separated by $1 \mathrm{~min}$, during which the neuron was bathed in $5 \mu \mathrm{M}$ chlorisondamine as indicated by the solid bars. The chlorisondamine was washed off for about $200 \mathrm{msec}$ before the next nicotine application.

modulate NnAChRs. First, $\mathrm{Ca}^{2+}$ influx into the cell through nAChRs is strongly voltage dependent (Decker and Dani, 1990; Vernino et al., 1994), but the modulation by $\mathrm{Ca}^{2+}$ is not (Fig. $1 C$ ). At $-70 \mathrm{mV}$ there is a large $\mathrm{Ca}^{2+}$ influx into the cell, but at $+70 \mathrm{mV}$ very little $\mathrm{Ca}^{2+}$ enters. If the currents from different chromaffin cells are normalized to their amplitudes in $1 \mathrm{mM} \mathrm{Ca}^{2+}$, then the enhancement of the currents in $10 \mathrm{~mm}$ $\mathrm{Ca}^{2+}$ is $2.6 \pm 0.3(n-28)$ at $-70 \mathrm{mV}, 3.1 \pm 0.2(n-32)$ at $-50 \mathrm{mV}$, and $2.8 \pm 0.3(n=15)$ at $+70 \mathrm{mV}$. SCG neurons are similarly modulated at $-70 \mathrm{mV}: 2.7 \pm 0.3(n=3)$. Second, the modulation by $\mathrm{Ca}^{2+}$ is unaffected by internal perfusion of the cell with $\mathrm{Ca}^{2+}$ chelators. In Figure $\mathrm{I}$ and in most cases, the cells were perfused with $10 \mathrm{~mm}$ BAPTA, but the same enhancement and lack of voltage dependence were seen with $20 \mathrm{mM}$ BAPTA $(n=3), 20 \mathrm{mM}$ EDTA $(n=3)$, and $10 \mathrm{mM}$ EDTA + $10 \mathrm{mM} \mathrm{EGTA}(n=2)$ with or without $4 \mathrm{~mm} \mathrm{ATP-}$ $\mathrm{Mg}$. These data were all combined to give the averages listed above. In summary, voltage and intracellular $\mathrm{Ca}^{2+}$ buffering do not influence the modulation, indicating that $\mathrm{Ca}^{2+}$ is acting externally and not through an intracellular enzyme cascade (Mulle et al., 1992b; Vernino et al., 1992).

Figure 1 also indicates other types of modulation and variability that are seen superimposed on the enhancement of NnAChR currents by external $\mathrm{Ca}^{2+}$. Although the current increase caused by $\mathrm{Ca}^{2+}$ is similar in Figure $1, C$ and $D$, the rate and degree of desensitization are much different. Desensitization is thought to arise from intrinsic properties of the receptor channel. Figure 1 shows that for each cell desensitization is greater with increased $\mathrm{Ca}^{2+}$ and at more negative potentials, as has been found for muscle nAChRs (Fiekers et al., 1980; Léna and Changeux, 1993). There is, however, much variability from cell to cell. This variability is thought to arise from intercellular enzyme activity, such as phosphorylation speeding the rate of muscle nAChR desensitization (Huganir, 1988). Thus, the currents can differ significantly in appearance while still giving comparable magnitudes of external $\mathrm{Ca}^{2+}$ modulation.

$\mathrm{Ca}^{2+}$ increases the likelihood of $\mathrm{NnAChR}$ seing open and does not activate a previously unresponsive population of NnAChRs

$\mathrm{Ca}^{2+}$ could enhance cholinergic responses by activating an otherwise unresponsive population of NnAChRs. There is a precedent for this type of modulation: treatment of ganglionic neurons with cAMP can convert a population of unresponsive NnAChR channels into responsive channels (Margiotta et al., 1987; Berg et al., 1989). The open channel blocker, chlorison- 
Figure 4. The probability of a $\mathrm{Nn}$ AChR channel being open is increased in elevated $\mathrm{Ca}^{2+}$. Single-channel cur rents are shown from an outside/out patch of membrane excised from an adrenal chronalfin cell and exposed to 10 $\mu \mathrm{M}$ DMPP in a solution containing either $1 \mathrm{~mm}$ or $10 \mathrm{mM} \mathrm{Ca}^{2+}$. The patch was moved alternately between the two solutions and was held in each solution for 8-47 sec. Each record shows the first $5 \mathrm{sec}$ of single-channel activity for the first 10 solution changes. The holding potential was $-70 \mathrm{mV}$. Consistent with other experiments that are not shown, the single-channel activity runs down with time in both solutions, but more rapidly in $1 \mathrm{mM} \mathrm{Ca}^{2}$. The amplitude of the single-channel events is larger in 1 Inм $\mathrm{Ca}^{2}$, but the probability of being open is greater in $10 \mathrm{~mm} \mathrm{Ca}^{2+}$. Integration of the current over the full length of the recording revealed that NnAChRs are 6 times more likely to be open in the $10 \mathrm{~mm} \mathrm{Ca}^{2+}$ solution.
$1 \mathrm{Ca}$
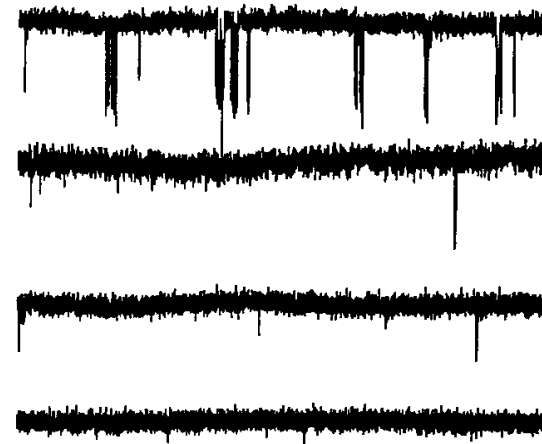

$10 \mathrm{Ca}$
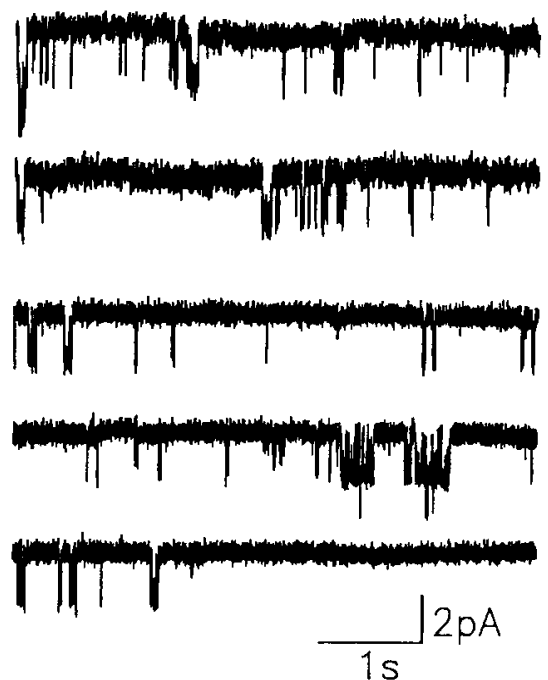

damine, was used to determine whether $\mathrm{Ca}^{3+}$ modulates already active NnAChRs or converts an unresponsive population of channels. Chlorisondamine enters NnAChR channels after they open and blocks them like a cork in a bottle. Also, chlorisondamine becomes trapped in the pore after the nAChR closes and continues to block until the channel is reopened and chlorisondamine has time to diffuse away (shown with muscle nAChRs by Neely and Lingle, 1986).

Our strategy for testing whether or not $\mathrm{Ca}^{2+}$ enhances currents by opening a new population of NnAChRs was as follows. Use chlorisondamine to block all the NnAChR channels that open in a solution of $1 \mathrm{mM} \mathrm{Ca}^{2+}$ and, then, see whether large nicotinic currents can still be seen in a solution of $5 \mathrm{~mm}$ $\mathrm{Ca}^{2+}$. If large nicotinic currents are seen in $5 \mathrm{mM} \mathrm{Ca}^{2+}$, then that current is passing through a new population of unblocked NnAChRs that did not open in the low $\mathrm{Ca}^{2+}$ solution. In separate experiments, chlorisondamine's mechanism of action was examined with NnAChRs to verify the work of Neely and Lingle (1986) on muscle nAChRs. In Figure 2, a SCG sympathetic neuron is stimulated by $56 \mu \mathrm{M}$ nicotine producing four nicotinic currents each separated by $1 \mathrm{~min}$. The solid bars represent $1 \mathrm{~min}$ of exposure to $5 \mu \mathrm{M}$ chlorisondamine that is terminated $200 \mathrm{msec}$ before the next agonist application. Figure 2 shows that chlorisondamine does not inhibit NnAChRs that have not opened. Therefore, chlorisondamine can be used to identify NnAChRs that have opened by blocking them and hecoming trapped within the pore.

In Figure $3 A$ application of $32 \mu \mathrm{M}$ DMPP to a SCG sympathetic neuron induces a current that is three times larger in a solution containing $5 \mathrm{~mm} \mathrm{Ca}^{2+}$ as compared with the current in $1 \mathrm{mM} \mathrm{Ca}^{2+}$. Then, repeated applications of agonist in the presence of chlorisondamine were made until all the channels that opened in $1 \mathrm{mM} \mathrm{Ca}^{2+}$ became blocked (Fig. $3 B$ ). Next, chlorisondamine was washed away, and the modulation by $\mathrm{Ca}^{2}$, was retested (Fig. 3C). After $15 \mathrm{sec}$ of wash, the first application of agonist activates only a small current in $1 \mathrm{~mm}$ $\mathrm{Ca}^{2+}$. The enhancement of that current by $5 \mathrm{mM} \mathrm{Ca}^{2+}$ is threefold as before, but the size of the current is small. After 10 exposures to agonist and $25 \mathrm{~min}$ of recovery from chlorison- damine, the currents are larger, but the modulation by $\mathrm{Ca}^{2}$ remains the same (threefold). Since only the channels that open in $1 \mathrm{mM} \mathrm{Ca}^{2+}$ were blocked by chlorisondamine. it is clear that elevated $\mathrm{Ca}^{2+}$ does not cause the activation of another population of previously unresponsive channels. If another population of channels had become active, chlorisondamine would not have decreased the extra current originally seen in $5 \mathrm{~mm}$ $\mathrm{Ca}^{2+}$ (Fig. 3A). Similar results giving identical conclusions were obtained in four other cells using $5 \mu \mathrm{M}$ chlorisondamine with either $32 \mu \mathrm{M}$ DMPP or $56 \mu \mathrm{M}$ nicotine. The recovery from blockade by chlorisondamine continued during the course of these experiments, but the recovery was slow because the neurons where always held at $-70 \mathrm{mV}$ in these experiments. Recovery was faster and more complete when the holding potential was depolarized to drive chlorisondamine out of the channel.

Although $\mathrm{Ca}^{2+}$ does not increase the population of responsive NnAChRs, single-channel recordings in excised patches of membrane indicated that $\mathrm{Ca}^{2+}$ does increase the probability of responsive NnAChRs being open. Figure 4 shows singlechannel currents induced in a single excised patch of membrane from a chromaffin cell. The agonist concentration. 10 $\mu M$ DMPP, remained constant as the patch was moved back and forth between solutions containing 1 or $10 \mathrm{~mm} \mathrm{Ca}{ }^{2+}$. Each record represents the first $5 \mathrm{sec}$ after a solution change. The fraction of time that a NnAChR channel is open is greater in $10 \mathrm{mM} \mathrm{Ca}^{2+}$. Over the course of the experiment, integration of the single-channel currents for the same length of time indicated that a channel is open six times more often in $10 \mathrm{~mm}$ $\mathrm{Ca}^{2+}$. The frequency of channel openings (bursts) increased 4.0 \pm 1.2 fold, and the burst length increased slightly, $1.7 \pm 0.3$ fold. In a total of four patches, integration of the currents gave a $3.4 \pm 1.2$ fold increase in the probability of a channel being open in $10 \mathrm{~mm}$ versus $1 \mathrm{~mm} \mathrm{Ca}{ }^{2+}$. This increased probability of opening quantitatively accounts for the $\mathrm{Ca}^{2+}$ modulation we see with macroscopic currents. The amplitude of the singlechannel currents is larger in low $\mathrm{Ca}^{2}$, as has been explained previously (Decker and Dani, 1990; Vernino et al., 1992).

Calcium modulation in chromafin cells appears the same as 
for SCG sympathetic neurons (Vernino et al., 1992), but much effort was made to obtain comparable single-channel results with membrane patches excised from SCG neurons. Stable single-channel records were impossible with the SCG neurons, however, because the patches had a low density of channels that "run down" very rapidly. In much less than a minute no channel events could be seen. Therefore, we could not obtain single-channel numbers as described for the chromaffin cells, but channel openings were more frequent and could be followed longer in high calcium with the SCG neurons. It also was not possible to characterize the run down process is SCG neurons because the process was so rapid, but we have characterized the effect in habenula neurons (Lester and Dani, 1994). Mulle et al. (1992b) had similar problems with run down in habenula neurons, where they compared 5-10 $\mathrm{sec}$ of $\mathrm{NnAChR}$ activity in 0 versus $4 \mathrm{mM} \mathrm{Ca}^{2+}$. Similar to our findings with chromaffin cells, they found a threefold increase in the opening frequency of the NnAChRs in higher $\mathrm{Ca}^{2+} \mathrm{ex}$ plained the modulatory effect.

\section{External $\mathrm{Ca}^{2 *}$ alters cholinergic synaptic transmission consistent with the postsynaptic modulation of NnAChRs}

Since external $\mathrm{Ca}^{2+}$ modulates $\mathrm{NnAChRs,} \mathrm{changes} \mathrm{in} \mathrm{external}$ $\mathrm{Ca}^{2+}$ could alter cholinergic synaptic transmission. Figure $5 \mathrm{~A}$ shows cholinergic, nicotinic spontaneous synaptic currents (SSCs) between SCG sympathetic neurons that were grown in culture to form cholinergic/cholinoceptive synapses (Hawrot and Patterson, 1979; Furshpan et al., 1986). In the presence of the NnAChR antagonist, hexamethonium, no large SSCs were ever seen. Propagated excitation was inhibited by blocking voltage-dependent $\mathrm{Na}^{+}$channels with I $\mu \mathrm{M}$ T'IX. The SSC's were obtained at a holding potential of $-70 \mathrm{mV}$ while the external solution was alternated 18 times between agonist-free solutions containing either 2 or $5 \mathrm{mM} \mathrm{Ca}^{2+}$. The amplitudes of the SSCs were used to build histograms with bin widths of 3 pA. The most populated bin for each of the two histograms represents the most commonly observe SSC amplitude: $7 \mathrm{pA}$ in $2 \mathrm{mM} \mathrm{Ca}^{2+}$ and $10 \mathrm{pA}$ in $5 \mathrm{mM} \mathrm{Ca}^{2+}$ (Fig. 5B). When all the current amplitudes were averaged together, the bin containing the average-size current was at $17 \mathrm{pA}$ in $2 \mathrm{mM} \mathrm{Ca}^{2+}$ and at $24 \mathrm{pA}$ in $5 \mathrm{mM} \mathrm{Ca}^{2+}$ (Fig. 5C). After hundreds of SSCs were obtained, $32 \mu \mathrm{M}$ nicotine was exogenously applied to the voltage-clamped neuron in $2 \mathrm{mM} \mathrm{Ca}^{2+}$ and then in $5 \mathrm{mM} \mathrm{Ca}^{2+}$ (Fig. $5 D$ ). As described earlier, external $\mathrm{Ca}^{2}{ }^{+}$enhanced the wholecell current induced by nicotine: the current was $700 \mathrm{pA}$ in 2 $\mathrm{mM} \mathrm{Ca}^{2}$ and $1070 \mathrm{pA}$ in $5 \mathrm{mM} \mathrm{Ca}^{2+}$. The ratio $1070 / 700$ can be defined as a modulation factor $(f)$ that accounts for changes in the amplitudes of the SSCs caused by external $\mathrm{Ca}^{2+}$ modulating NnAChRs. If the amplitude of the most common SSC in $2 \mathrm{mM} \mathrm{Ca}^{2}$ ' is multiplied by $f$, the product equals the amplitude of the most common SSC in $5 \mathrm{mM} \mathrm{Ca}^{2+}: 7 \mathrm{pA} \times 1070 /$ $700=10.7 \approx 10 \mathrm{pA}$. The same relationship holds for the average-size SSC: $17 \mathrm{pA} \times 1070 / 700=26.0 \approx 24 \mathrm{pA}$.

The two SSC amplitude distributions are shown in Figure $6 A$. The number of SSCs in the peak bin is normalized to 100 (ordinate). The distribution in $2 \mathrm{mM} \mathrm{Ca}^{2}+$ lies at smaller amplitudes than the distribution in $5 \mathrm{~mm} \mathrm{Ca}^{2+}$. Then, all the amplitudes of the distribution obtained in $2 \mathrm{mM} \mathrm{Ca}^{2+}$ were multiplied by $f$, and the distributions were plotted again in Figure $6 B$. The two distributions then overlap. The modulation factor accounts for the differences in the amplitudes of the two SSC distributions, indicating that extracellular $\mathrm{Ca}^{2+}$ alters the am-

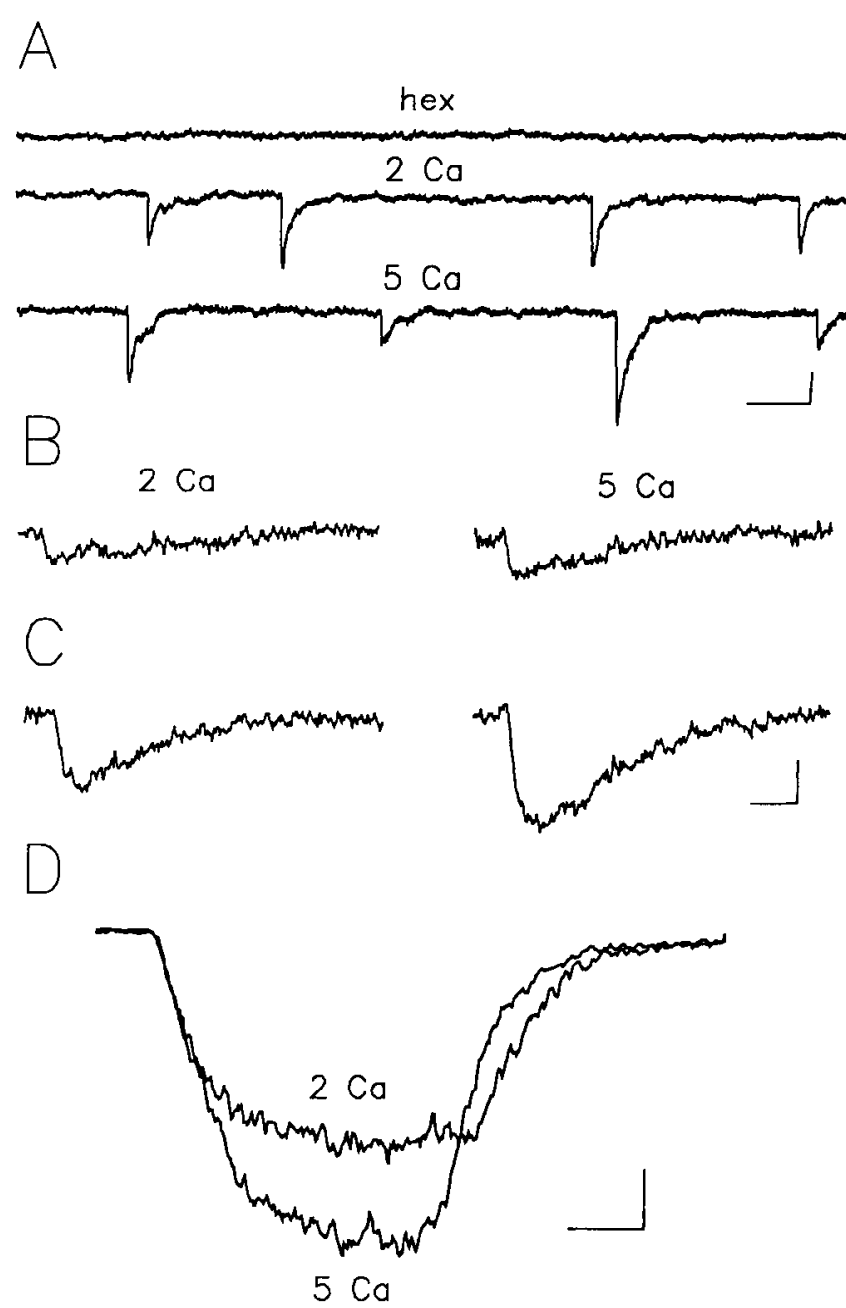

Figure 5. Cholinergic, nicotinic, spontaneous synaptic currents (SSCs) from sympathetic neurons are modulated by external $\mathrm{Ca}^{2+} . A$, Three continuous $3.2 \mathrm{sec}$ SSC records are shown for a sympathetic neuron held at $-70 \mathrm{mV}$. When the nicotinic antagonist, $20 \mu \mathrm{M}$ hexamethonium (hex), was present, SSCs were not seen. SSCs were obtained as the external (agonist free) solution was alternated between $2 \mathrm{~mm}$ and $5 \mathrm{~mm}$ $\mathrm{Ca}^{2+}$. On average the bathing solution was rapidly switched every 80 sec. Calibration: $20 \mathrm{pA}, 250 \mathrm{msec}$. $B$, An example is shown of the most common amplitude of the SSCs obtained in $2 \mathrm{~mm}$ or $5 \mathrm{~mm} \mathrm{Ca}{ }^{2+}$. C. An example of the average-size amplitude of the SSCs obtained in 2 $\mathrm{mm}$ or $5 \mathrm{~mm} \mathrm{Ca}^{2+}$. Calibration: $10 \mathrm{pA}, 10 \mathrm{msec}$ for both sets of examples. $D$, After obtaining many SSCs, $32 \mu \mathrm{M}$ nicotine was exogenously applied to the sympathetic neuron, which was whole-cell clamped at $-70 \mathrm{mV}$. The current was $700 \mathrm{pA}$ in $2 \mathrm{mM} \mathrm{Ca}^{2+}$ and 1070 $\mathrm{pA}$ in $5 \mathrm{~mm} \mathrm{Ca}^{3+}$. Calibration: $200 \mathrm{pA}, 250 \mathrm{mscc}$.

plitudes of the SSCs by acting postsynaptically to modulate NnAChRs. Such skewed and wide SSC distributions are not seen for mature neuromuscular junctions, but they are common in the central nervous system. Bekkers et al. (1990) investigated the source of the variability for glutamatergic synapses in cultured hippocampal neurons. They reported that the variability of quantal size is the major determinant. Ilume and Honig (1991) proposed similar mechanisms to explain the extremely hroad amplitude histograms obtained from preganglionic and sympathetic neurons. Those reports also discuss other potential sources of the variability.

The influence of external $\mathrm{Ca}^{2+}$ on the cholinergic SSCs can be fully explained by $\mathrm{Ca}^{2+}$ directly modulating the postsynaptic 

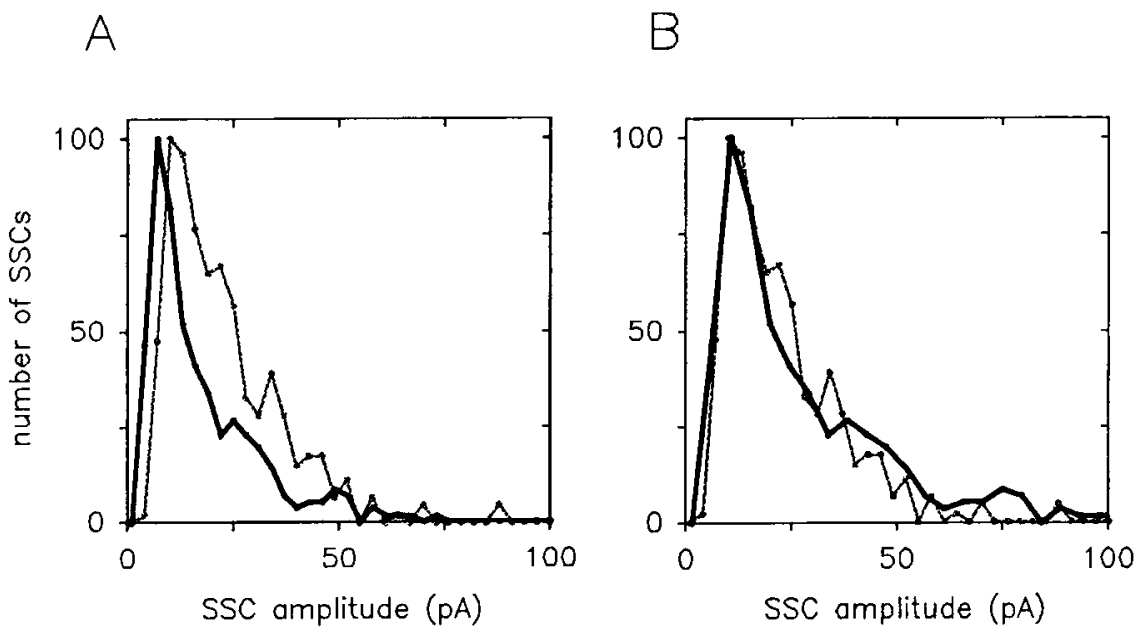

Figure 6. Postsynaptic modulation of NnAChRs by $\mathrm{Ca}^{2+}$ accounts for the difference in the amplitudes of the spontaneous synaptic currents. $A$, The amplitude distribution of SSCs is shown for $2 \mathrm{mM} \mathrm{Ca}^{2+}$ (thick line) and $5 \mathrm{~mm} \mathrm{Ca}^{2+}$ (thin line). The most populated bin is scaled to 100 on the $y$-axis (number of SSCs), which is plotted against SSC amplitude in pA on the x-axis. The distribution obtained in $2 \mathrm{~mm}$ Ca' falls to the left (smaller amplitudes) of the distribution obtained in $5 \mathrm{mM} \mathrm{Ca}^{2+} . B$, When the amplitudes of the SSCs in $2 \mathrm{mM} \mathrm{Ca}^{2+}$ are adjusted for $\mathrm{Ca}^{2+}$ modulation of NnAChRs by multiplying all the amplitudes by the modulation factor, $f$, the $2 \mathrm{mM} \mathrm{Ca}^{2+}$ distribution then falls on top of the $5 \mathrm{~mm} \mathrm{Ca}^{2+}$ distribution. The distributions contained 286 events in $2 \mathrm{~mm} \mathrm{Ca}^{2}$ collected during a total of $627 \mathrm{sec}$ and 333 events in $5 \mathrm{~mm} \mathrm{Ca}^{2+}$ collected during at total of $788 \mathrm{sec}$.

NnAChRs. There was no effect on the frequency of SSCs, which was $27 \pm 3$ events per minute in $2 \mathrm{Ca}^{2+}$ and $25 \pm 2$ events per minute in $5 \mathrm{Ca}^{2+}$. Thus, presynaptic factors did not appear to influence the change in the amplitude of the SSCs in the two solutions, which is consistent with previous work (Redman, 1990).

In 4 out of 4 other neurons, the SSC distribution in 1 or 2 $\mathrm{mM} \mathrm{Ca}{ }^{2+}$ was displaced to lower current amplitudes as compared with the distribution in $5 \mathrm{~mm} \mathrm{Ca}^{2+}$. Figure 7 shows an example of another neuron where we were able to determine in 2 and $5 \mathrm{~mm} \mathrm{Ca}^{2+}$ both the amplitude distributions and the modulation factor, $f$, which was $535 / 400$ at a holding potential of $-70 \mathrm{mV}$ using $32 \mu \mathrm{M}$ nicotine. The average-size currents for the two distributions were $16 \mathrm{pA}$ in $2 \mathrm{mM} \mathrm{Ca}^{2+}$ and $21 \mathrm{p} \Lambda$ in $5 \mathrm{mM} \mathrm{Ca}^{2}$. Again, the modulation factor accounted for the difference in the two amplitude distributions, as is exemplified by the average currents: 16 pA $\times 535 / 400=21$ pA. Figure 7 shows the cumulative histograms of SSC amplitudes. The total number of SSCs of a particular size or smaller are added together to produce the cumulative histograms. This procedure diminishes the fluctuations from bin to bin and more clearly shows the shift to lower SSC amplitudes in $2 \mathrm{~mm}$ versus $5 \mathrm{~mm}$ $\mathrm{Ca}^{2+}$ (Fig. 7A). When the amplitudes obtained in $2 \mathrm{~mm} \mathrm{Ca}{ }^{2+}$ are multiplied by the modulation factor $(f=535 / 400)$, the two
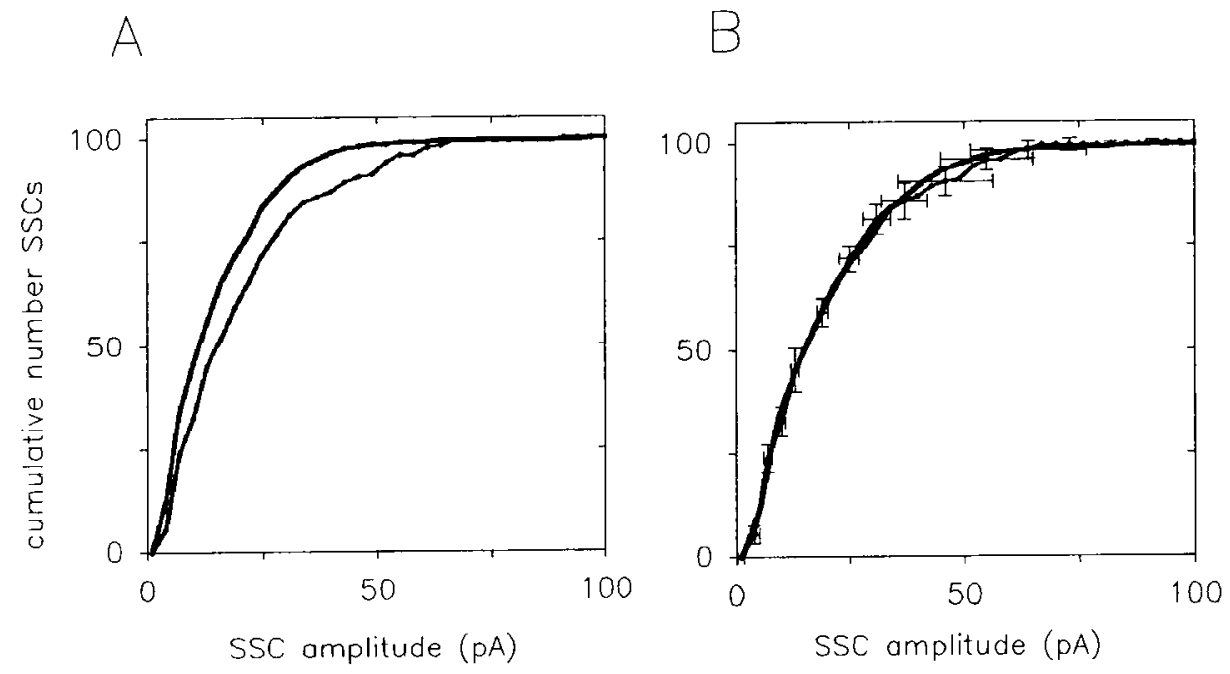

Figure 7. Cumulative histograms also show that postsynaptic modulation of NnAChRs by $\mathrm{Ca}^{2+}$ accounts for the difference in the amplitudes of the spontaneous synaptic currents. $A$, The amplitude distribution of SSCs are transformed into cumulative histograms by adding the number of SSCs that are equal to or less than the amplitude bin in question. The total number of SSCs is normalized to 100 for both distributions. The distribution in $2 \mathrm{mM} \mathrm{Ca}^{2+}$ (thick line) is at smaller amplitudes than the distribution in $5 \mathrm{mM} \mathrm{Ca}^{2+}$ (thin line). B. When the amplitudes of the SSCs in $2 \mathrm{mM} \mathrm{Ca}^{2+}$ are adjusted for $\mathrm{Ca}^{2+}$ modulation of $\mathrm{NnAChRs}$ by multiplying all the amplitudes by the modulation factor, $f$, the $2 \mathrm{~mm} \mathrm{Ca}^{2+}$ distribution then falls on top of the $5 \mathrm{~mm} \mathrm{Ca}{ }^{2+}$ distribution. The distributions contained 190 events in $2 \mathrm{~mm} \mathrm{Ca}^{2+}$ collected during a total of 108 $\mathrm{sec}$ and 167 events in $5 \mathrm{mM} \mathrm{Ca}^{2+}$ collected during a total of $108 \mathrm{sec}$. The error bars were calculated by obtaining the deviations of the 2 mM $\mathrm{Ca}^{2+}$ distribution from its corresponding $5 \mathrm{mM} \mathrm{Ca}^{2+}$ distribution for three separate experiments (i.e., $n=3$ ). 
distributions overlap (Fig. $7 B$ ). The distribution obtained in 5 $\mathrm{mM} \mathrm{Ca}{ }^{2+}$ is shown with error bars, illustrating that the modulation factor accounts for the shift in the amplitude histograms with very small errors from trial to trial $(n=3$ comparing 2 $\mathrm{mMCa} \mathrm{Ca}^{2+}$ to $5 \mathrm{mM} \mathrm{Ca}^{2+}$ ).

\section{Discussion}

The results document two properties of neuronal nicotinic receptors and synapses. First, modulation of NnAChRs by external $\mathrm{Ca}^{2+}$ does not involve activation of a previously refractory or unresponsive population of $\mathrm{NnAChRs}$. Rather, $\mathrm{Ca}^{2+}$ acts via a direct mechanism that increases the probability of the channels being open. Mulle et al. (1992B) similarly reported that $\mathrm{Ca}^{2+}$ modulation enhances opening frequency of NnAChRs from rat medial habenular neurons. Chromaffin cells and habenular neurons are likely to express different NnAChR subtypes (Role, 1992), but the modulation by $\mathrm{Ca}^{2+}$ seems to arise from the same mechanism (i.e., a change in the opening frequency). Vernino et al. (1992) reported this form of $\mathrm{Ca}^{2+}$ modulation with four different $\mathrm{NnAChR}$ subtypes expressed in oocytes. The accumulation of evidence indicates that this form of $\mathrm{Ca}^{2+}$ modulation may be common among many NnAChR subtypes in the nervous system. The second finding of this work is that the modulation by $\mathrm{Ca}^{2+}$ alters spontaneous cholinergic synaptic currents. That result shows that synaptic processes can be affected by this type of $\mathrm{Ca}^{2+}$ modulation, suggesting that activity-dependent decreases in external $\mathrm{Ca}^{2+}$ may negatively affect nicotinic responses to further $\mathrm{ACh}$ release.

\section{Biological implications}

It is interesting that muscle nAChRs have a lower $\mathrm{Ca}^{2+}$ permeability and are not modulated by external $\mathrm{Ca}^{2+}$ in the same way as neuronal nAChRs (Decker and Dani, 1990; Vernino et al., 1992). Since the neuromuscular synapse must work well even during extended use, it would not be adaptive to have decreased excitability caused by external $\mathrm{Ca}^{2+}$ modulation during times of high activity. The lower $\mathrm{Ca}^{2+}$ permeability of the muscle receptor suggests that the nerve-muscle synapse need not undergo the same activity-dependent forms of plasticity that may be required at neuronal cholinergic synapses.

Neuronal nAChRs have a higher $\mathrm{Ca}^{2+}$ permeability, and at least one neuronal $n A C h R$ subtype has a $\mathrm{Ca}^{2+}$ permeability comparable to that of the NMDA subtype of glutamate receptors (Vijayaraghavan et al., 1992; Séguéla et al., 1993). At highly active cholinergic synapses, $\mathrm{Ca}^{2+}$ intlux through $\mathrm{Nn}$ AChRs could activate intracellular mechanisms leading to synaptic plasticity in a manner previously reserved for glutamatergic synapses (Malinow et al., 1988; Malenka et al., 1989; Madison et al., 1991). In addition, our results indicate that at nicotinic synapses where high activity has decreased external $\mathrm{Ca}^{2+}$ there will be a diminished response of NnAChRs to further $\mathrm{ACh}$ release. This mechanism will be accompanied by other processes, such as the influence of external $\mathrm{Ca}^{2+}$ on transmitter release and $\mathrm{nAChR}$ desensitization (Augustine et al., 1987; Léna and Changeux, 1993). Since NnAChRs have both presynaptic and postsynaptic locations in the CNS (see Sargent, 1993), the influence of this hypothesized rapid negative feedback mechanism could be quite varied. A reasonable scenario that could decrease cholinergic synaptic excitability after high activity is as follows. High synaptic activity decreases extracellular $\mathrm{Ca}^{2+}$. Subsequent excitation of the presynaptic terminal produces a smaller $\mathrm{Ca}^{2+}$ influx and a concomitant decrease in
ACh release. $\mathrm{Ca}^{2+}$ modulation makes the postsynaptic $\mathrm{Nn}$ AChRs less likely to open in response to $\mathrm{ACh}$. Consequently, cholinergic synaptic transmission is diminished. Since many NnAChRs are located presynaptic where they can enhance release of other neurotransmitters, the mechanism of $\mathrm{Ca}^{2+}$ modulation could be widespread, influencing the activity-dependent release of many neurotransmitters. There could be other roles for such a mechanism. One role could be to limit the size of the intracellular $\mathrm{Ca}^{2+}$ signal so that intracellular $\mathrm{Ca}^{2+}$ does not become dangerously high, as is expected during some forms of excitotoxic neuron death seen at glutamatergic synapses (Regan and Choi, 1991; Choi, 1992).

\section{References}

Adams DJ, Nutter TJ (1992) Calcium permeability and modulation of nicotinic acetylcholine receptor-channels in rat parasympathetic neurons. J Physiol (Paris) 86:67-76.

Amador M, Dani JA (1991) MK-801 inhibits nicotinic acetylcholineinduced currents. Synapse 7:207-215.

Augustine GJ, Charlton MP, Smith SJ (1987) Calcium action in synaptic transmitter release. Annu Rev Neurosci 10:633-693.

Bekkers JM, Richerson GB, Stevens CF (1990) Origin of variability in quantal size in cultured hippocampal neurons and hippocampal slices. Proc Natl Acad Sci USA 87:5359-5362.

Benninger C, Kadis J, Prince DA (1980) Extracellular calcium and potassium changes in hippocampal slices. Brain Res 187:165-182.

Berg DK, Boyd RT, Halvorsen SW, Higgins LS, Margiotta JF (1989) Regulating the number and function of neuronal acetylcholine receptors. Trends Neurosci 12:16-21.

Choi DW (1992) Excitotoxic cell death. J Neurobiol 23:1261-1276.

Decker ER, and Dani JA (1990) Calcium permeability of the nicotinic acetylcholine receptor: the single-channel calcium influx is significant. J Neurosci 10:3413-3420.

Fiekers JF, Spannbauer PM, Scubon-Mulieri B, Parsons RL (1980) Voltage-dependence of desensitization: influence of calcium and activation kinetics. J Gen Physiol 75:511-529.

Furshpan EJ, Landis SC, Matsumoto SG, Potter DD (1986) Synaptic functions in rat sympathetic neurons in microcultures. I. Secretion of norepinephrine and acetylcholine. J Neurosci 6:106I-1079

Greenberg A. Zinder $O(1982) \alpha-$ and $\beta$-receptor control of catecholamine secretion from isolated adrenal medulla cells. Cell Tissue Res 226:655-665.

Hamill OP, Marty A, Neher E, Sakmann B, Sigworth FJ (1981) Improved patch-clamp techniques for high-resolution current recordings from cells and cell-free membrane patches. Pfluegers Arch 391: $85-100$

Hawrot E, Patterson PH (1979) Long term culture of dissociated sympathetic neurons. Methods Enzymol 58:574-584.

Heinemann U, Stabel J, Rausche G (1990) Activity-dependent ionic changes and neuronal plasticity in rat hippocampus. Prog Brain Res 83:197-214.

Huganir RL (1988) Regulation of the nicotinic acetylcholine receptor channel by protein phosphorylation. Cur Top Membr Transplant 33. $147-163$.

Hume RI, Honig MG (1991) Physiological properties of newly formed synapses between sympathetic preganglionic neurons and sympathetic ganglion neurons. J Neurobiol 22:249-262

Léna C, Changeux JP (1993) Allosteric modulations of the nicotinic acetylcholine receptor. Trends Neurosci 16:181-186.

Lester RAJ, Dani JA (1994) Time-dependent changes in central nicotinic acetylcholine channel kinetics in excised patches. Neuropharmacology 33:27-34.

Livsey CT, Huang B, Xu J, Karwoski CJ (1990) Light-evoked changes in extracellular calcium concentration in frog retina. Vision Res 6:853-861.

Madison DV, Malenka RC, Nicoll RA (1991) Mechanisms underlying long-term potentiation of synaptic transmission. Annu Rev Neurosci 14:379-397

Malenka RC, Kauer JA, Perkel DJ, Mauk MD, Kelly PT, Nicoll RA. Waxham MN (1989) An essential role for postsynaptic calmodulin and protein kinase. Nature 340:554-557. 
Malinow R, Madison DV, Tsien RW (1988) Persistent protein kinase activity underlying long-term potentiation. Nature 335:820-824.

Margiotta JF, Berg DK, Dionne VE (1987) Cyclic AMP regulates the proportion of functional acetylcholine receptors on chicken ciliary ganglion neurons. Proc Natl Acad Sci USA 84:8155-8159.

Mody 1, Heinemann U (1986) Laminar profiles of the changes in extracellular calcium concentration induced by repetitive stimulation and excitatory amino acids in the rat dentate gyrus. Neurosci Lett 69:137-142.

Mulle C, Choquet D, Korn H, Changeux JP (1992a) Calcium influx through nicotinic receptor in rat central neurons: its relevance to cellular regulation. Neuron 8:135 143 .

Mulle C, Léna C, Changeux JP (1992b) Potentiation of nicotinic receptor response by external calcium in rat central neurons. Neuron 8:937-945.

Neely A, Lingle CJ (1986) Trapping of an open-channel blocker at the frog neuromuscular acetylcholine channel. Biophys J 50:981986.

Pumain R, Heinemann U (1985) Stimulus- and amino acid-induced calcium and potassium changes in the rat neocortex. $J$ Neurophysiol $53: 1-16$.
Redman S (1990) Quantal analysis of synaptic potentials in neurons of the central nervous system. Physiol Rev 70:165-198.

Regan RF, Choi DW (1991) Glutamate neurotoxicity in spinal cord cell culture. Neuroscience 43:585-591.

Role LW (1992) Diversity in primary structure and function of neuronal nicotinic acetylcholine receptor channels. Curr Opin Neurobiol 2:254-262.

Sargent $P$ (1993) The diversity of neuronal nicotinic acetylcholine receptors. Annu Rev Neurosci 16:403-443.

Séguéla P, Wadiche J, Dineley-Miller K, Dani JA, Patrick JW (1993) Molecular cloning, functional properties and distribution of rat brain $\alpha 7$ : a nicotinic cation channel highly permeable to calcium. J Neurosci 13:596-604.

Vernino S, Amador M, Luetje CW, Patrick J, Dani JA (1992) Calcium modulation and high calcium permeability of neuronal nicotinic acetylcholine receptors. Neuron 8:127-134.

Vernino S, Rogers M, Radcliffe K, Dani JA (1994) Quantitative measurement of calcium flux through muscle and neuronal nicotinic acetylcholine receptors. J Neurosci 14:5514-5524.

Vijayaraghavan S, Pugh PC, Zhang Z, Rathouz MM, Berg DK (1992) Nicotinic receptors that bind $\alpha$-bungarotoxin on neurons raise intracellular free calcium. Neuron 8:353-362. 